\title{
MATERIAIS DE CONSTRUÇÃO SUSTENTÁVEIS EM EMPREENDIMENTOS DE HABITAÇÃO DE INTERESSE SOCIAL FINANCIADOS PELO PMCMV
}

\section{SUSTAINABLE BUILDING MATERIALS USED ON SOCIAL HOUSING FUNDED BY PMCMV}

\section{Rafaela Lima dos Santos, MSc. (UFS); Júlio Cesar Oliveira Santana (UFS)}

\section{Palavras Chave}

Materiais de construção sustentáveis, habitação de interesse social, questionário, sustentabilidade

\section{Key Words}

Sustainable building materials, low-cost house, questionnaire, sustainability

\section{RESUMO}

O presente trabalho apresenta um levantamento quantitativo dos empreendimentos de habitação de interesse social financiados pelo Programa Minha Casa Minha Vida (PMCMV) localizados em Aracaju e região metropolitana que fazem uso de materiais de construção sustentáveis (MCS). Para tanto, foi feita investigação na literatura sobre a utilização de materiais de construção sustentáveis e a construção de habitações de interesse social (HIS). O artigo avalia as possibilidades e as consequências da substituição de materiais de construção convencionais por materiais de construção sustentáveis em HIS. A pesquisa também levanta dados, através de questionário eletrônico, com o intuído de revelar o caráter sustentável dos empreendimentos de HIS que estão sendo construídos atualmente em Aracaju e na sua região metropolitana, exclusivamente aqueles financiados pelo PMCMV, bem como o grau de utilização, o que motivou a escolha desses materiais e relaciona quais deles estão sendo mais utilizados nesses empreendimentos de habitação. Os resultados mostraram que algumas empresas utilizaram MCS nesses empreendimentos do PMCMV, porém seu uso é ainda incipiente, mesmo que a qualidade dos MCS tenha sido avaliada entre boa e muito boa pela maioria dos respondentes. O uso de MCS nos empreendimentos habitacionais de interesse social financiados pelo PMCMV pode ainda ser ampliado e apresentar maior relevância em prol do Desenvolvimento Sustentável.

\section{ABSTRACT}

This paper presents a quantitative survey of social housing projects financed by the MCMV Program (MCMV) located in Aracaju and metropolitan area, which use sustainable building materials (MCS). Therefore, research has been made in the literature on the use of sustainable building materials and the construction of social housing (HIS). Assesses the likelihood and consequences of replacing conventional building materials for sustainable building materials in HIS. The research also raises data through electronic questionnaire, in order to reveal the character of sustainable housing developments currently being built in Aracaju and its metropolitan area, exclusively those funded by the PMCMV, as well, the degree of utilization, what motivated the choice of these materials, and lists which ones are being used more in those housing projects. The results showed that the companies used MCS in these projects of the PMCMV. However, their use is still timid, even though the quality of MCS has been assessed between good and very good by most respondents. The use of MCS in housing projects of social interest funded by PMCMV can be further extended and more relevant for the sake of Sustainable Development. 


\section{INTRODUÇÃO}

As cidades abrigam um número cada vez maior de pessoas e os problemas decorrentes dessa intensa urbanização englobam o crescimento também de condições precárias de habitação. A construção de habitações de qualidade para atender esse contingente marginalizado da população tem papel fundamental para o crescimento e desenvolvimento socioeconômico de uma nação.

No contraponto, o planeta enfrenta uma crise ambiental. Alterações climáticas, decorrentes da devastação do meio ambiente natural, da poluição e do aquecimento global provocado por emissão de gases do efeito estufa, acarretam na ameaça e na extinção de espécies da fauna e da flora, em desastres ambientais e desequilíbrio ecológico.

O Desenvolvimento Sustentável propõe a continuidade do crescimento em favorecimento das nações ainda em desenvolvimento, porém respeitando os limites do consumo e exploração dos recursos naturais. Nesse sentido, medidas mitigadoras devem tomadas para aliviar os impactos ambientais.

Nesse contexto, a Indústria da Construção Civil é uma das maiores consumidoras dos recursos naturais e também a responsável por transformar o ambiente natural em ambiente construído. Se essa indústria pudesse desenvolver e optar por materiais de construção que provocassem menor impacto ambiental, seria possível reduz consideravelmente seu impacto. Esses materiais foram denominados de Materiais de Construção Sustentáveis (MCS) nessa pesquisa.

O objetivo desta pesquisa é realizar um levantamento quantitativo e qualitativo, a partir da percepção das empresas do setor da construção civil que atuam na grande Aracaju/SE, dos níveis de inserção da sustentabilidade na construção a partir do uso de materiais sustentáveis adotados por essas empresas, em especial as que estão atualmente construindo empreendimentos de habitação de interesse social financiados pela Caixa Econômica Federal, incluídas no programa do Governo Federal, Minha Casa Minha Vida (MCMV). Busca-se também investigar o entendimento dos conceitos relacionados à sustentabilidade por essas empresas de modo a confrontar o que é idealizado por elas como medidas sustentáveis com o que é realmente praticado

\section{REVISÃO BIBLIOGRÁFICA}

O desenvolvimento é apontado como o principal responsável pela degradação do meio ambiente. Diante da crise ambiental, Meadows et al. (1972) apud Brüseke (1995) propõem o congelamento do crescimento da população global e do capital industrial, mostram a realidade dos recursos limitados e rediscutem a velha tese de Malthus do perigo do crescimento desenfreado da população mundial. A tese do crescimento zero significava um ataque direto à filosofia do crescimento contínuo da sociedade industrial e uma crítica indireta a todas as teorias do desenvolvimento industrial que se basearam nela.

No entanto, críticas surgiram a partir de teóricos que defendiam o modelo do crescimento (BRÜSEKE, 1995). O argumento estava embasado na injustiça que seria imposta às nações em desenvolvimento, ao restringi-las de alcançarem os níveis de qualidade de vida dos países desenvolvidos. Nesse contexto, surge uma alternativa intermediária entre a cessão do desenvolvimento em prol da manutenção do meio ambiente ou sua continuidade em favorecimento dos menos desenvolvidos.

O termo Desenvolvimento Sustentável foi utilizado pela primeira vez no relatório "pe" e o conceito nele estabelecido foi adotado pela ONU. É definido como "aquele que atende às necessidades do presente sem comprometer a possibilidade de as gerações futuras atenderem às suas próprias necessidades" (BRUNDTLAND, 1987).

A Indústria da Construção Civil pode exercer um importante papel na preservação do meio ambiente, visto que sua escala de produção utiliza uma grande quantidade de recursos naturais e seus produtos têm elevado impacto no consumo de energia e água. Desta maneira, mudanças no tratamento de questões ambientais representam importantes oportunidades de desenvolvimento para vários setores da cadeia produtiva (LAMBERTS et al., 2007).

Para Lamberts et al. (2007), as edificações sustentáveis são concebidas de modo a racionalizar o uso de recursos naturais, a fazer uso de materiais ecologicamente corretos e a alterar o mínimo possível o ambiente no qual estão inseridas. A preocupação com o meio ambiente deve estar presente durante todas as etapas de uma construção, desde o projeto até sua utilização. Os autores consideram também que o momento da especificação dos materiais é importante, devendo-se privilegiar materiais pró-meio ambiente assim como recicláveis em geral.

\subsection{Habitação de interesse social}

Os programas de habitação no Brasil sempre foram controversos na construção de Habitação de Interesse Social (HIS) ao longo da história no Brasil. O Banco Nacional da Habitação (BNH) beneficiou amplamente as classes médias e construiu conjuntos habitacionais populares de baixa qualidade em áreas periféricas. Uma política habitacional que relegou às populações de menor 
renda favelas e loteamentos precários. O BNH financiou, nos seus 22 anos de existência, 4,5 milhões de moradias, $1 / 4$ de toda a produção, incluindo a produção informal (SANTO AMORE et al., 2015).

Atualmente, o Programa Minha Casa Minha Vida (PMCMV), lançado em 2009, contratou, em apenas cinco anos, quase $80 \%$ das unidades (3,5 milhões) que o BNH financiou em toda sua existência, sendo metade dessas unidades já entregue (SANTO AMORE et al., 2015). Segundo Rolnik (2015), o programa caracterizou-se tão eficiente quanto uma "máquina de construção de habitações".

Os conjuntos habitacionais, devido ao mérito dos empreendimentos de HIS do passado, receberam o estigma de produtos de baixa qualidade, com elevado custo de manutenção. Ficaram caracterizados pela repetição de "casinhas amontoadas", distantes dos centros urbanizados, e, consequentemente, desconectados da infraestrutura e dos equipamentos urbanos necessários para promover qualidade de vida aos seus usuários.

Rolnik (2015) constatou que o PMCMV vem exercendo um papel ativo na reprodução da segregação em função da renda e na reafirmação da periferia como lugar dos pobres nas cidades brasileiras. Diferentemente do que ocorria em experiências anteriores como a do $\mathrm{BNH}$, os empreendimentos do PMCMV vêm sendo implantados em áreas periféricas, porém contíguas à malha urbana pré-existente, decorrente de um processo de urbanização cumulativo.

\subsection{Habitação de interesse social sustentável}

A construção de Habitações de Interesse Social tem um papel fundamental para atuar diretamente na dimensão social do Desenvolvimento Sustentável. As metas sustentáveis, para que se caracterizem como tal, devem agir nas três dimensões da sustentabilidade, promovendo ações ambientalmente responsáveis, socialmente justas e economicamente viáveis.

Algumas ferramentas que podem vir a auxiliar na incorporação dos conceitos sustentáveis aos empreendimentos do PMCMV por parte dos empreendedores são as metodologias de certificação ambiental de edificações, em especial, o Selo Casa Azul. De maneira geral, entende-se que a principal vantagem das ferramentas e dos métodos de avaliação reside na orientação aos empreendedores, projetistas e construtores quanto aos aspectos a serem considerados na produção de edificações sustentáveis (SALGADO, et al., 2012).

O Selo Casa Azul é uma metodologia de certificação socioambiental que classifica empreendimentos habitacionais financiados pela Caixa Econômica Federal (CEF) a partir de critérios pré-estabelecidos. Segundo Caixa Econômica Federal (2015), a criação desse selo foi a forma encontrada pela instituição de promover a melhoria da qualidade da habitação e racionalizar a utilização de recursos naturais nas construções. Isso se daria através do reconhecimento (utilizado como uma ferramenta de marketing imobiliário) dos projetos que adotem soluções eficientes nas fases de construção, uso, operação e manutenção.

Os projetos são avaliados em seis categorias que englobam 53 critérios possíveis. As seis categorias avaliadas são: Qualidade Urbana, Projeto e Conforto, Eficiência Energética, Gestão da Água, Conservação dos Recursos Materiais e Práticas Sociais. As categorias estão divididas em critérios, sendo alguns obrigatórios e outros de livre escolha, que devem ser optados de acordo com as características do empreendimento para garantir os resultados efetivos da sua aplicação (TRIANA; GHISI, 2013).

O Selo Casa Azul busca incentivar este equilíbrio entre os componentes ambientais, sociais e econômicos nos projetos habitacionais, colocando ações de comprometimento e benefício nesses três eixos (TRIANA; GHISI, 2013).

No entanto, acredita-se que os critérios dessas metodologias ainda são muito frágeis. Correspondem a medidas, em grande parte, correntemente praticadas pelas construtoras devido às exigências de cumprimento com obrigações legais, ou ainda, praticadas como estratégias de gestão da construção. Por isso, contribuem pouco para o incremento dos níveis de sustentabilidade que os empreendimentos deveriam buscar para serem realmente reconhecidos como sustentáveis. Contudo, a pouca contribuição da metodologia de certificação Casa Azul não invalida o seu mérito em incentivar práticas cada vez mais sustentáveis na Construção Civil.

A sustentabilidade deve ser uma busca estratégica a ser adotada pela empresa para a construção de um empreendimento, devendo o planejamento e a gestão estarem coerentes com essa estratégia, e não restringidas por ações dos mesmos (MOTTA; AGUILAR, 2009).

\subsection{Materiais de construção sustentáveis}

Nos últimos anos, têm-se atribuído importância cada vez maior aos materiais de construção e seus impactos no meio ambiente. Na tomada de decisão por certo produto e sistema construtivo, não só os aspectos técnicos e econômicos devem ser levados em conta, mas também os ecológicos. A realidade é que a parcela do mercado mobilizada na mitigação dos impactos ambientais é ainda minúscula. Para muitas cadeias da área de materiais de construção que dependem do varejo, ela é ainda menor. 
A definição de um produto como sustentável ou ecológico depende de um parâmetro, uma referência. Ou seja, um produto dito sustentável apresenta características menos poluentes ou teve menor consumo de água, energia ou recursos naturais na sua produção, comparando-o a produtos convencionais (CAIADO, 2014).

De acordo com Pisani (2005), a procura de materiais e técnicas construtivas que minimizem os impactos ambientais provenientes de uma construção tem se intensificado nos últimos anos. Para Hernandes (2015), a disseminação dos materiais ditos "verdes" é consequência da necessidade de soluções mais sustentáveis no setor da construção civil.

Dada a grande variedade de materiais ditos sustentáveis presentes no mercado, Loturco (2015), define dez critérios técnicos de sustentabilidade para a seleção de materiais: consumo de água e recursos energéticos para a fabricação; geração de poluentes na fabricação; redução de matérias-primas e uso de materiais recicláveis; distância entre obra e a fábrica e procedência do produto; geração e gestão de resíduos na obra; economia de energia ou água de operação; durabilidade e facilidade de manutenção; reciclabilidade do produto e destinação pós-consumo; emissão de substâncias nocivas à saúde humana; legalidade e responsabilidade socioambiental do fabricante.

Boa parte da seleção de materiais é realizada na fase de projeto e orçamento (mais de 70\%). Porém, o alto índice de seleção dentro da fase de execução no canteiro de obras (aproximadamente 30\%) demonstra que a construtora, frequentemente, altera, durante a obra, os materiais selecionados em projeto.

A carência de dados para realizar a seleção com base em critérios de sustentabilidade (ex. fabricante, uso de ACV, lista de materiais sustentáveis, quantidade de $\mathrm{CO} 2$ direta) é um fato que prejudica o setor de projetos. Por essa falta de dados, normalmente a seleção é feita baseada em poucos critérios ou em apenas um critério e de forma muito simplificada, acarretando em problemas (CBCS, 2014).

A seguir, serão detalhados alguns materiais utilizados em canteiros de obras e que possuem apelo sustentável. São eles: madeira plástica, elementos construtivos em bambu, tijolo ecológico e agregados de resíduos da construção civil.

\subsubsection{Madeira plástica}

A fabricação da madeira plástica é realizada a partir do processamento da madeira e de diversos tipos de plásticos, como o Polietileno de alta densidade (PEAD),
Polipropileno (PP), Policloreto de vinila (PVC), entre outros. Portanto, sua produção é considerada ecológica, já que ajuda a eliminar o lixo plástico e reduzir o desmatamento indevido das florestas (SERVIÇO BRASILEIRO DE RESPOSTAS TÉCNICAS, 2012).

A madeira plástica vem sendo utilizada como uma alternativa para a reciclagem de polímeros, substituindo a madeira convencional. Esse novo material apresenta características importantes como: não pode ser atacado por cupins ou fungos; não absorve umidade; é resistente a agentes químicos em geral e raios UV; tem baixo consumo energético em sua produção; é reciclável; não solta farpas (GUIMARÃES, 2013).

No setor da construção civil, a madeira plástica pode ser utilizada como pilares e vigas de sustentação, formas, escoramentos, esquadrias, decks de piscina, pisos, entre outros usos. Há possibilidade, também, de aplicação de um acabamento diferenciado, conferindo novas características estéticas à peça (SERVIÇO BRASILEIRO DE RESPOSTAS TÉCNICAS, 2012).

Guimarães (2013) apresenta dados relacionados à madeira plástica formada por plástico e pó de madeira, chamada de Wood Plastic Composite (WPC), em alguns países. Em todo o mundo, são produzidos cerca de 1,5 milhões de toneladas de WPC, com destaque para a Alemanha, líder europeu, que aplica tal material principalmente na indústria automotiva. A produção chinesa abrange uma maior área, englobando a construção civil, com produtos como janelas, portas, sistemas termo isolantes, entre outros.

A comercialização em larga escala da madeira plástica nos EUA, Europa e Ásia pode representar uma tendência para os países em desenvolvimento, surgindo, assim, uma alternativa ambiental para a redução do volume de resíduos destinados aos aterros (GUIMARÃES, 2013). Ao aliar aspectos socioambientais e inovação tecnológica, a madeira plástica, portanto, tem boas perspectivas de mercado ao substituir a madeira convencional e outros materiais em diversas aplicações.

\subsubsection{Elementos construtivos em bambu}

$O$ bambu é considerado um material de grande potencial e de fácil manuseio, e, como material de construção, apresenta excelentes características físicas e mecânicas. Além de ser um material renovável, de baixo custo e não poluente, pode ser utilizado em sistemas estruturais devido à sua boa resistência à compressão (BARBOZA et al., 2008).

De acordo com Hernandes (2015), o piso em lâminas de bambu vem ganhando destaque dentre os produtos 
renováveis disponíveis no mercado. Tal material é apresentado como uma alternativa mais sustentável que outros sistemas para piso, visto que o bambu é uma matéria-prima renovável, durável e com baixa emissão de carbono. Em seu trabalho, Hernandes (2015) avalia se a emissão dos gases de efeito estufa no transporte do produto entre a região produtora e o local de consumo pode comprometer o caráter ecológico do piso de bambu.

Barboza et al. (2008) realizaram uma avaliação do uso de bambu como material alternativo na construção de habitação de interesse social, utilizando-o em elementos de cobertura e de painéis de vedação. Os autores observaram que, ao utilizar um material disponível no local de implantação da obra e de fácil manuseio, houve contribuição para o barateamento da obra e para a utilização de uma nova forma de construções ambientalmente mais adequadas.

\subsubsection{Tijolo ecológico}

O tijolo ecológico é o tijolo de solo-cimento, composto por areia, cimento e água, sem necessidade de queima. Essa denominação deve-se, principalmente, ao fato de que sua produção não necessita de fornos, não consumindo lenha nem outro combustível. Além disso, os tijolos que quebram podem ser novamente transformados, diferente dos blocos cerâmicos tradicionais, gerando, assim, menos entulho (SEBRAE, 2015).

Grande (2003) afirma que os tijolos de solo-cimento têm aplicações técnicas simples, permitindo o desenvolvimento de sistemas construtivos com as seguintes vantagens: controle de perdas, disponibilidade de abastecimento; baixo custo em comparação às alvenarias convencionais; durabilidade e segurança estrutural; eficiência construtiva; facilidade de manuseio. SEBRAE (2015) acrescenta que as vantagens do tijolo ecológico não estão só relacionadas ao meio ambiente, mas também ao conforto, à estética e ao aspecto financeiro.

Por ser o componente de maior proporção na mistura, o solo deve ser escolhido visando a utilização da menor quantidade possível de cimento. Pires (2004) indica características aos solos mais adequados na fabricação de tijolos ecológicos, como passar inteiramente na peneira de $4,8 \mathrm{~mm}$, e desaconselha o uso de solos que contenham quantidade de argila superior a 50\%. Solos arenosos requerem, na maioria das vezes, menor quantidade de cimento que os argilosos e siltosos.

Mesmo com tantas vantagens destacadas com relação aos tijolos ecológicos, o surgimento de novos materiais industrializados no mercado causou um desinteresse por construções em solo-cimento, sendo, atualmente, mais utilizado em obras de pavimentação, reforços e melhorias de solo, barragens e contensões (GRANDE, 2003).

\subsubsection{Agregados de resíduo da construção civil}

As construções, demolições e reformas geram, em conjunto, uma grande quantidade de resíduos que, se não dispostos de forma adequada, podem causar sérios problemas ambientais. Esses resíduos são passíveis de reaproveitamento na forma de matéria-prima na construção, reduzindo, assim, o consumo de recursos naturais e ainda dando solução aos problemas ambientais urbanos relacionados à geração e disposição de resíduos da construção (GOMES et al., 2002).

No Brasil, a Resolução no 307/2002/CONAMA define Resíduos da Construção Civil (RCC) como aqueles provenientes de construções, reformas, reparos e demolições de obras de construção civil, e os resultantes da preparação e da escavação de terrenos, como tijolos, blocos cerâmicos, concreto em geral, solos, entre outros, comumente denominados de entulhos de obra.

As usinas de reciclagem de RCC produzem agregados reciclados com alta variabilidade mineral, fator que restringe seu uso como material de construção. Esse produto, no entanto, pode ser usado em obras de manutenção, de pavimentação e infraestrutura. Nesse caso, os requisitos técnicos para empregabilidade independem do controle de qualidade rigoroso (MELO, 2011).

A norma NBR 15116 (ABNT, 2004) estabelece requisitos para o emprego de agregados reciclados de resíduos sólidos da construção civil destinados a obras de pavimentação viária e ao preparo de concreto sem função estrutural. Tal tipo de concreto é destinado a usos como enchimentos, contrapiso, calçadas e fabricação de artefatos não estruturais.

Gomes et al. (2002), em seu trabalho, verificaram a influência da substituição do agregado graúdo por entulho, em concretos de média e baixa resistências, analisando suas propriedades no estado fresco e endurecido. Os resultados mostraram que se faz necessária uma análise da absorção do entulho, uma vez que o material inserido na mistura esteja em estado seco, ocorre absorção de parte da água de emassamento, afetando a trabalhabilidade do concreto.

A norma NBR 15116 (ABNT, 2004) ratifica essa alta capacidade absorvente dos agregados reciclados, recomendando uma pré-molhagem do material. Os autores citados notaram também que a substituição total pelo entulho se apresenta mais favorável que a parcial visto que traz maior economia de matéria-prima consumida na produção do concreto. 


\section{PROCEDIMENTOS METODOLÓGICOS}

A pesquisa foi realizada por meio de um questionário eletrônico na plataforma Formulários Google, sendo organizada em cinco blocos: (1) constrói empreendimentos habitacionais pelo programa MCMV; (2) faz uso de materiais de construção sustentáveis nos empreendimentos de HIS do MCMV; (3) não faz uso de materiais de construção sustentáveis nos empreendimentos de HIS do MCMV; (4) habitações de interesse social sustentáveis; e (6) sustentabilidade e certificação ambiental.

O questionário foi elaborado para ser aplicado via internet, de forma prática e rápida, não levando mais do que 10 minutos para ser respondido. Sua concepção foi realizada de forma que, a depender da resposta, o entrevistado fosse encaminhado para determinadas perguntas, de forma automática. As questões elaboradas são predominantemente de múltipla escolha e, algumas, permitem selecionar mais de uma opção ou escrever algum texto caso necessário. A pesquisa ficou aberta por 14 dias, do dia 22 de junho a 06 de julho de 2015.

A partir de uma relação de 38 empresas, conhecidas por atuarem nesse nicho de mercado, realizou-se o contato por telefone com cada uma delas para que o formulário fosse enviado a um funcionário apto a respondê-lo, preferencialmente um engenheiro ou arquiteto. Após algumas tentativas de contato, a pesquisa foi enviada, com êxito, para 27 construtoras, obtendo-se, ao final do período, 14 respondentes, cujas identidades foram totalmente preservadas.

\section{RESULTADOS}

O formulário teve início questionando se a empresa está atualmente construindo algum empreendimento voltado para habitações de interesse social financiado pelo programa Minha Casa Minha Vida do Governo Federal.

Do total de 14 respondentes, nove responderam que sim, estão construindo esse tipo de empreendimento. Para os outros cinco, que assinalaram não estar com obras do programa MCMV, houve a finalização automática do formulário (Figura 1).

Figura 01 - Resumo das respostas da 1a pergunta.

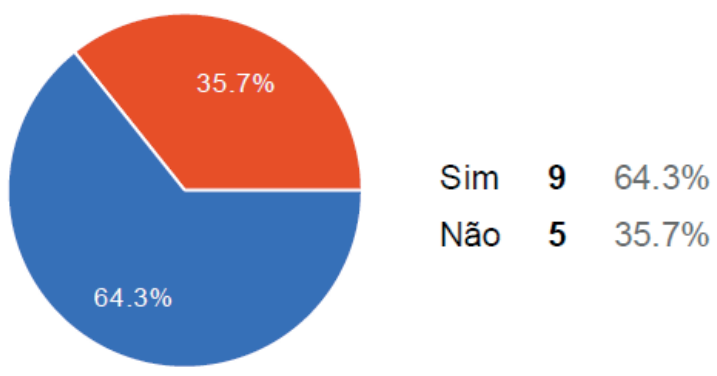

Fonte: Autores.
A pergunta seguinte investigou quantos empreendimentos do programa MCMV a empresa estaria construindo, naquele momento. Na Figura 2, vê-se a distribuição das respostas das nove empresas: $66,7 \%$ estão fazendo somente um empreendimento, $22,2 \%$ estão fazendo dois e $11,1 \%$ afirmaram estar construindo mais de quatro.

Figura 02 - Resumo das respostas da $2^{a}$ pergunta.

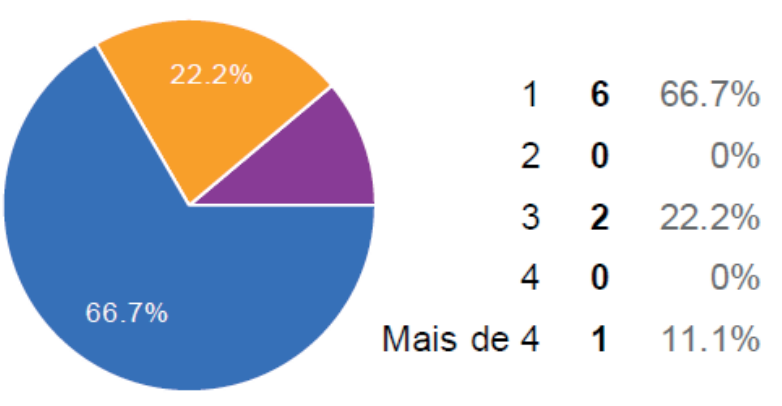

Fonte: Autores

Com relação ao comprometimento com o desenvolvimento sustentável, oito empresas marcaram que se consideram comprometidas, enquanto apenas uma afirmou não se considerar comprometida (Figura 3).

Figura 03 - Resumo das respostas da 3a pergunta.

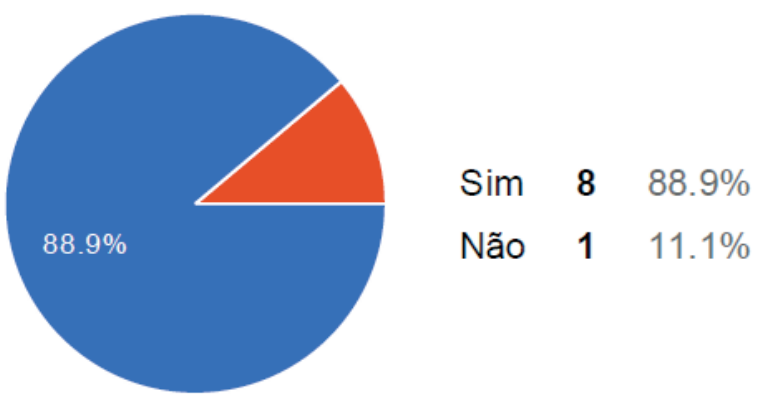

Fonte: Autores

Na pergunta seguinte, os respondentes puderam marcar as ações que a empresa desenvolve para contribuir com o desenvolvimento sustentável. Das opções fornecidas, a mais assinalada foi a gestão de resíduos, com oito marcações, seguida pela redução de desperdício e melhorias no gerenciamento de obra, ambas sinalizadas sete vezes. No entanto, nenhuma empresa afirmou estar desenvolvendo ações para melhorar a qualidade do ar interior, somente uma (11,1\% dos respondentes) assinalou estar reduzindo as emissões de $\mathrm{CO} 2$ e somente duas (22,2\% dos respondentes) alegaram inserir soluções ecologicamente corretas. 
É possível presumir que a obrigatoriedade de gestão dos resíduos pela resolução n 307/2002/CONAMA, que estabelece diretrizes, critérios e procedimentos para a gestão dos resíduos da construção civil, provavelmente tenha influenciado no resultado da questão anterior (4a). O interesse das empresas não é necessariamente contribuir para o desenvolvimento sustentável, mas cumprir uma exigência legal. Apesar de a maioria das empresas se considerarem comprometidas com o DS, poucas ou nenhuma delas consideraram a qualidade do ar interior, o controle de emissões de $\mathrm{CO}^{2}$, ou a implantação de soluções ecologicamente corretas nas suas práticas.

Com relação ao uso de materiais de construção sustentáveis, sete empresas, representando $77,8 \%$ da amostra, afirmaram utilizar essa categoria de material em seus empreendimentos de habitação de interesse social (Figura 4).

Figura 04 - Resumo das respostas da $5^{a}$ pergunta.

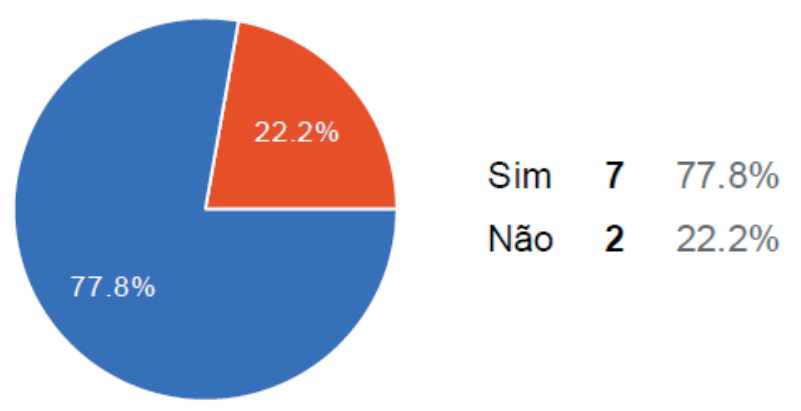

Fonte: Autores.

Com a possibilidade de marcação de mais de um item, os sete respondentes que marcaram "sim" na pergunta anterior, indicaram quais materiais de construção sustentáveis utilizam em seus empreendimentos financiados pelo PMCMV.

O uso de madeira plástica e o tijolo ecológico foram assinalados por uma empresa cada, enquanto que os resíduos de construção civil são os mais utilizados, com 85,7\% da preferência. Forma de polipropileno para argolamento e madeira de reflorestamento, que não estavam dentre as opções de resposta, também foram citados, uma vez cada, por duas empresas distintas.

O que mais motivou essas empresas a adotarem esses materiais de construção sustentáveis nesses empreendimentos foi o seu baixo impacto ambiental, $85,7 \%$, seguido do baixo custo, $71,4 \%$. Com relação às vantagens e benefícios da utilização de materiais de construção sustentáveis em substituição aos convencionais, as opções assinaladas foram bem variadas, com destaque para questões ambientais e econômicas. Também foram considerados: a produtividade, o desempenho, a aceitação pelo mercado consumidor, o marketing verde e a valorização imobiliária.

Os respondentes puderam avaliar o nível de qualidade dos materiais de construção sustentáveis disponíveis no mercado. Sendo nota 1 considerado ruim e nota 10 excelente. A menor nota atribuída foi 3, dada por uma empresa, a única também abaixo dos 5 pontos. Já a maior nota foi 8, concedida por 3 empresas. A Figura 5 indica a distribuição da avaliação dos materiais pelas empresas.

Figura 05 - Resumo das respostas da 9a pergunta.

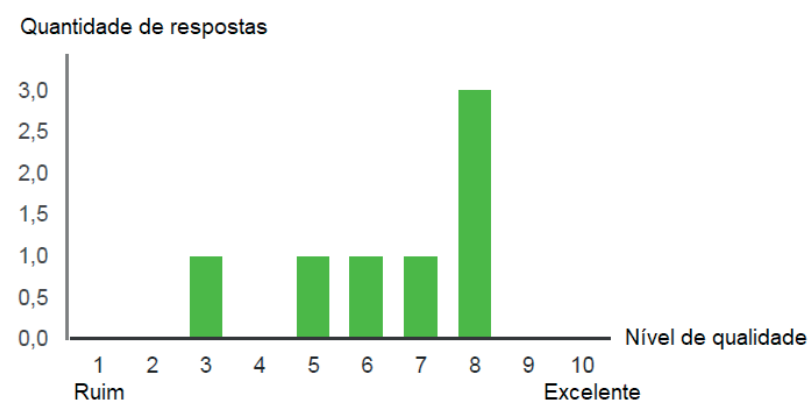

Fonte: Autores.

A despeito das empresas terem alegado que a principal motivação para adoção de materiais de construção sustentáveis nos empreendimentos do PMCMV terem sido o baixo impacto ambiental com baixo custo e a maioria ter avaliado a qualidade dos materiais entre 5 e 8 em uma escala de 10, ou seja, considerando a mesma, no mínimo, satisfatória, as respostas da $6^{\mathrm{a}}$ questão revelou que o nível de utilização de materiais sustentáveis, com exceção dos RCC, é ainda pouco expressiva, deixando um amplo espaço para ter seu uso mais intensivo e abrangente. Dessa forma, o caráter sustentável desses empreendimentos seria bem mais relevante reduzindo a pegada de carbono do empreendimento.

As duas empresas que afirmaram não utilizar materiais de construção sustentáveis em seus empreendimentos do MCMV, puderam indicar quais fatores desmotivaram a não adoção desses materiais. Ambas assinalaram a indisponibilidade de fornecedores e outros fatores como custo elevado, desconhecimento a respeito e falta de mão de obra especializada.

Essas dificuldades, porém, não foram entraves às empresas que utilizaram MCS. Isso pode se configurar como falta de interesse em deixar de trabalhar com materiais convencionais e buscar materiais alternativos mais sustentáveis, aumentando assim o nível de comprometimento com o DS por parte das empresas que não utilizaram MCS. Uma vez que a informação, contatos com empresas 
e treinamento de mão de obra estão cada vez mais disponível na atualidade, esse desinteresse se comprova pela a avaliação que as mesmas fizeram, na questão seguinte, considerando satisfatória a qualidade dos MCS.

A Figura 6 mostra as avaliações que essas duas empresas fizeram com relação ao nível de qualidade desses materiais, em que uma construtora apontou nível 5 enquanto que a outra assinalou nível 8. Assim, mesmo não utilizando MCS, as empresas demonstram que a qualidade não é ruim.

Figura 06 - Resumo das respostas da 11a pergunta

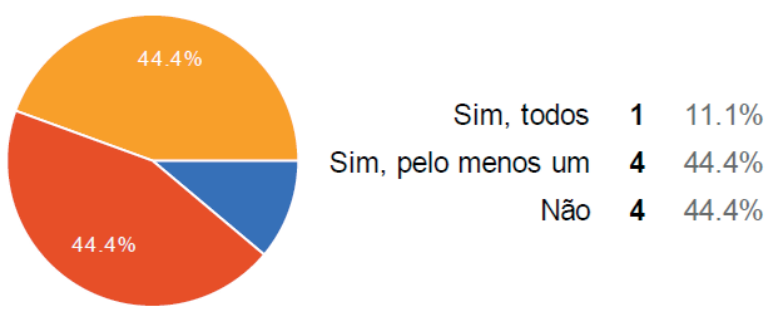

Fonte: Autores

As perguntas seguintes sobre sustentabilidade e certificação ambiental puderam ser respondidas por todas as 9 empresas que responderam sim à primeira pergunta. $A$ Figura 7 indica a opinião das empresas ao serem questionadas se consideram seus empreendimentos do programa MCMV como habitações de interesse social sustentáveis.

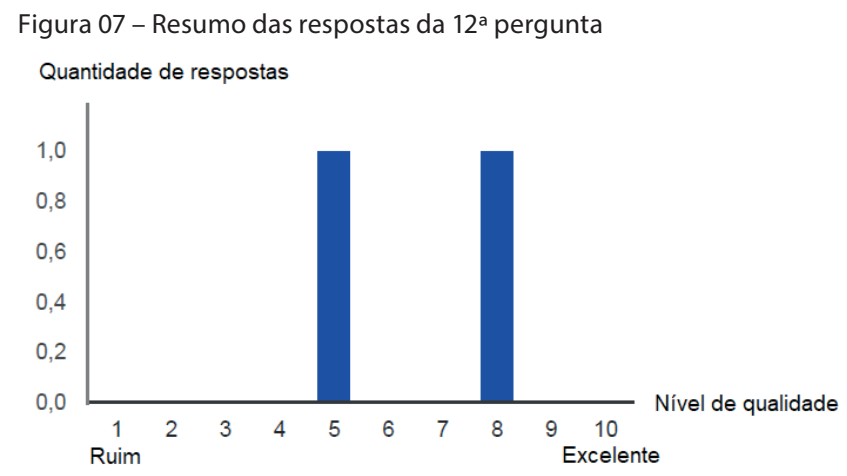

Fonte: Autores

As empresas que consideraram todos ou pelo menos um de seus empreendimentos como sustentáveis passaram para as próximas perguntas. As quatro que não consideraram esse fato tiveram seus formulários finalizados.

Dentre as soluções adotadas para atribuir a esse empreendimento um caráter sustentável, a gestão de resíduos foi a opção mais assinalada pelos respondentes: 4 empresas (80\% da amostra). Em seguida, com duas marcações cada, soluções ecologicamente corretas, soluções econômicas, soluções para incrementar as condições de saúde e bem-estar, soluções para reduzir o impacto da implantação no terreno, melhorias no gerenciamento, redução do desperdício e gestão do uso da água. Porém, nenhuma empresa marcou as opções: ações sociais, soluções para incrementar a qualidade do ar interior, implantação de tecnologias renováveis, ou transporte.

Com relação aos métodos de avaliação e certificação ambiental, as empresas puderam apontar quais ferramentas foram adotadas nesses empreendimentos. Apenas uma delas afirmou possuir o Selo Casa Azul. Outra mencionou o Selo Verde, que é um programa de rotulagem e certificação ambiental criado pela Associação Brasileira de Normas Técnicas. Por se tratar de uma metodologia voluntária de certificação e rotulagem de desempenho ambiental de produtos ou serviços (ABNT, 2015), não tendo nenhuma associação direta com construções ou edificações sustentáveis, essa resposta foi desconsiderada nesta pesquisa.

Os motivos pelos quais a empresa que adotou a certificação Selo Casa Azul para o projeto e/ou empreendimento foram: comprovar a qualidade ambiental da construção, diferenciar portfólio da empresa no mercado, associar a imagem da empresa à qualidade ambiental, melhorar o relacionamento com órgãos ambientais e comunidades, ter um reconhecimento internacional, contribuir para o desenvolvimento sustentável e a sobrevivência no planeta, proporcionar melhores condições de conforto e saúde aos moradores, redução das emissões de gases de efeito estufa, reduzir a poluição, melhorar aproveitamento da infraestrutura local, melhorar a qualidade de vida, melhorar gestão de resíduos sólidos, melhorar gestão de riscos ambientais.

Mesmo que a opção por seguir uma metodologia de certificação ambiental de edificações não garanta a inserção da sustentabilidade como solução estratégica adotada pela empresa nos seus empreendimentos, essa ação pelo menos demonstra, por não ser uma exigência legal, a vontade da empresa em contribuir com a diminuição dos impactos gerados ao meio ambiente pelo empreendimento, pela própria empresa e pela indústria da construção civil além de contribuir para a difusão de práticas mais sustentáveis. Infelizmente, somente uma empresa da amostra afirmou ter optado por certificar seu empreendimento.

\section{CONCLUSÕES}

A partir das respostas obtidas por meio de questionário eletrônico, foi possível constatar que as empresas 
que estavam construindo empreendimentos de habitação financiados pelo PMCMV na grande Aracaju no momento da pesquisa, apesar de, a maioria, se considerarem comprometidas com o DS, demonstraram que o interesse principal é sobretudo econômico e fazer cumprir as exigências legais, como a gestão de resíduos.

Algumas práticas associadas à melhoria de gestão da construção, por serem também incentivadas pela sustentabilidade, favorecem a redução do impacto das construções, porém são insuficientes. As empresas entrevistadas ainda não incorporaram a sustentabilidade como busca estratégica. Acredita-se que o real motivo do baixo índice de utilização de MCS nos empreendimentos de HIS do PMCMV se deve pela não inserção vertical da sustentabilidade como medida estratégica de gestão, planejamento e construção.

O uso de MCS foi relativamente pequeno diante das possibilidades, tendo em vista que a qualidade não foi aparentemente considerada um entrave e que existe conhecimento a respeito das vantagens econômicas, ambientais, desempenho, produtividade, aceitação pelo mercado consumidor, uso como marketing verde e valorização imobiliária relativas ao uso desses materiais em HIS.

Os materiais de construção sustentáveis têm o potencial de substituir grande quantidade de materiais convencionais em obras de HIS ou outros tipos de obras, promovendo, assim, a redução dos impactos ambientais, favorecendo a economia e a sociedade. Novas pesquisas podem apontar na direção da criação de novos MCS, na melhoria daqueles já existentes ou ainda buscar formas de fomentar um maior uso pela indústria da construção civil em especial nos empreendimentos voltados à HIS.

\section{AGRADECIMENTOS}

Os autores agradecem à Fundação de Apoio à Pesquisa e Inovação Tecnológica do Estado de Sergipe - FAPITEC/ SE pelo suporte financeiro e à Universidade Federal de Sergipe pelo suporte institucional necessário para o desenvolvimento desse artigo.

\section{REFERÊNCIAS}

ABNT - ASSOCIAÇÃO BRASILEIRA DE NORMAS TÉCNICAS. NBR 15116 - agregados reciclados de resíduos sólidos da construção civil - Utilização em pavimentação e prepare de concreto sem função estrutural - Requisitos. Rio de Janeiro, 2004.
ABNT - ASSOCIAÇÃO BRASILEIRA DE NORMAS TÉCNICAS. 2015. Disponível em: <http://www.abnt.org.br/ rotulo> Acesso em: 22 jul. 2015.

BARBOZA, A. S. R.; BARBIRATO, J. C. C.; SILVA, M. M. C. P. Avaliação do uso de bambu como material alternativo para a execução de habitação de interesse social. In: Ambiente Construído, Porto Alegre, v. 8, n. 1, p. 115-129, jan./mar. 2008.

BRUNDTLAND, G. H. (Ed.). Our Common Future: The World Commission on Environment and Development. Report, 20 mar. 1987.

BRÜSEKE, F. J. O Problema do Desenvolvimento Sustentável. In: Clovis Cavalcante. (Org.). Desenvolvimento e natureza: estudos para uma sociedade sustentável. São Paulo: Cortez, 1995, v., p. 29-40.

CAIADO, A. R. Contribuição ao estudo da rotulagem ambiental dos materiais de construção civil. 2014. Dissertação (Mestrado em Tecnologia da Arquitetura) Programa de Pós-Graduação em Arquitetura e Urbanismo da FAUUSP, Faculdade de Arquitetura e Urbanismo. Universidade Federal de São Paulo. São Paulo, 2014.

CAIXA ECONÔMICA FEDERAL. Selo Casa Azul. 2015. Disponível em: <http://www.caixa.gov.br/sustentabilidade/produtos-servicos/selo-casa-azul> Acesso em: 20/07/2015.

CONAMA - CONSELHO NACIONAL DO MEIO AMBIENTE). Resolução no 307/2002: Estabelece diretrizes, critérios e procedimentos para a gestão dos resíduos da construção civil. Legislação. Brasília, Distrito Federal, Brasil: DOU no 136, de 17 de julho de 2002, Seção 1, 95-96 p.

GOMES, A. de O.; DIAS, C. M. R.; MACHADO, A. T.; CARDOSO, R. J. C.; SANTANA, M. J. A. Caracterização do entulho visando a sua utilização como agregado graúdo para concreto de cimento Portland. In: IX Encontro Nacional de Tecnologia do Ambiente Construído, Foz do Iguaçu - Paraná, 2002.

GRANDE, F. M. (2003). Fabricação de tijolos modulares de solo-cimento por prensagem manual com e sem adição de sílica ativa. São Carlos, 2003. 165p. Dissertação (Mestrado) - Escola de Engenharia de São Carlos, Universidade de São Paulo. 
GUIMARÃES, L. F. C. Avaliação dos aspectos técnicos e econômicos na produção de madeira plástica por meio da utilização de materiais reciclados. Belo Horizonte - MG, Abril de 2013.

HERNANDES, T. Z. Piso de bambu chinês vs. piso de eucalipto brasileiro: estudo de caso comparativo das emissões de gases de efeito estufa no transporte. Ambiente Construído, Porto Alegre, v. 15, n. 1, p. 7-16, jan./mar. 2015. ISSN 1678-8621 Associação Nacional de Tecnologia do Ambiente Construído.

LAMBERTS, R.; TRIANA, M. A.; FOSSATI, M.; BATISTA, J. O. Sustentabilidade nas edificações: contexto internacional e algumas referências brasileiras na área. 2007.

LOTURCO, B. Projetos que buscam certificação de sustentabilidade devem pautar escolha de materiais por critérios técnicos e fugir de propaganda enganosa. Revista Techne, 215 ed., Fev. 2015, PINI, São Paulo.

MELO, A. V. S. Diretrizes Para a Produção de Agregado Reciclado em Usinas de Reciclagem de Resíduos da Construção Civil. 232f. il. 2011. Dissertação (Mestrado) Escola Politécnica da Universidade Federal da

MOTTA, S. R. F.; AGUILAR, M. T. P. Sustentabilidade e Processos de Projetos de Edificações. Gestão e tecnologia de projetos, v.4, p. 84-119, 2009.

PIRES, I. B. A. A utilização de tijolo ecológico como solução para construções de habitações populares. Salvador, 2004. Monografia (Graduação) - Engenharia Civil, Universidade Salvador - UNIFACS.

PISANI, M. A. J. Um material de construção de baixo impacto ambiental: O tijolo de solo-cimento. Sinergia, São Paulo, v. 6, n. 1, p. 53-59, jan./jun. 2005

ROLNIK, R. O Programa Minha Casa Minha Vida nas regiões metropolitanas de São Paulo e Campinas: aspectos socioespaciais e segregação. Cadernos Metrópole/Observatório das Metrópoles, São Paulo, p. 127 - 154, 18 de maio de 2015.

SALGADO, M. S.; CHATELET, A.; FERNANDEZ, P. G. J. Produção de edificações sustentáveis: desafios e alternativas. Ambiente Construído (Online), v. 12, p. 81-99, 2012.

SANTO AMORE, C. (Org.); SHIMBO, L. Z. (Org.); RUFINO, M. B. C. (Org.). Minha Casa... E a cidade? Avaliação do Programa Minha Casa Minha Vida em seis estados brasileiros. 1. ed. Rio de Janeiro: Letra Capital, 2015. 428p.

SEBRAE. Como montar uma fábrica de tijolos ecológicos. Disponível em: <http://www.sebrae.com.br> Acesso em: 08 jun. 2015.

SERVIÇO BRASILEIRO DE RESPOSTAS TÉCNICAS. Madeira plástica na construção civil. Resposta Técnica elaborada por: "Valério Freitas dos Santos". Porto Alegre: SENAI/RS, 2012. (Código da Resposta: 21076).

TRIANA, M. A.; GHISI, E. Benefícios para aplicação do Selo Casa Azul: Categorias Eficiência Energética e Projeto e Conforto. 2013 (Manual). 